\title{
Distribution of Mating Type Alleles and Fertility Status of Magnaporthe grisea Causing Gray Leaf Spot of Perennial Ryegrass and St. Augustinegrass Turf
}

\author{
G. Viji and W. Uddin, Department of Plant Pathology, The Pennsylvania State University, University Park 16802
}

\begin{abstract}
Viji, G., and Uddin, W. 2002. Distribution of mating type alleles and fertility status of Magnaporthe grisea causing gray leaf spot of perennial ryegrass and St. Augustinegrass turf. Plant Dis. $86: 827-832$.

Isolates of Magnaporthe grisea causing gray leaf spot of perennial ryegrass (PR) (Lolium perenne) and St. Augustinegrass (SA) (Stenotaphrum secundatum) were analyzed for mating compatibility and fertility. A total of 312 isolates of M. grisea from PR and 62 isolates from SA were paired with hermaphroditic tester strains from finger millet (Eleusine coracana), rice (Oryza sativa), and wheat (Triticum aestivum). All the PR isolates belonged to a single mating type, MAT1-2. Male fertility was observed in all these isolates. Asci and ascospores were not produced regardless of their developmental stage. Of the $139(44.6 \%)$ isolates from PR that formed perithecia with the fertile tester strains, $83(59.7 \%)$ were highly fertile, $33(23.7 \%)$ were intermediately fertile, and $23(16.5 \%)$ were low in fertility. Both mating types were observed among the isolates of SA, where MAT1-1 predominated the MAT1-2 type. An equal number of male and female fertile isolates were detected among these isolates obtained from a single location; however, none of the isolates behaved as hermaphrodites. Few ascospores were produced in crosses between two isolates of SA and a finger millet tester. Of the 62 monoconidial isolates of SA tested, $19(30.6 \%)$ isolates formed perithecia, of which $5(26.3 \%)$ were highly fertile, 7 $(36.8 \%)$ were intermediately fertile, $7(36.8 \%)$ were low in fertility, and $43(69.4 \%)$ were infertile. The results of this study indicate that the sexual stage may not be a significant factor contributing to the genetic variation the gray leaf spot pathogen population.
\end{abstract}

Additional keywords: Pyricularia grisea, ryegrass blast, turfgrass

Gray leaf spot, caused by the heterothallic ascomycete Magnaporthe grisea (T.T. Hebert) Yaegashi \& Udagawa (anamorph: Pyricularia grisea (Cooke) Sacc.), is a serious disease of perennial ryegrass ( $\mathrm{Lo}$ lium perenne L.) turf in various regions of the United States. Severe outbreaks of the disease causing extensive damage to turf have been reported in recent years $(13,27,28)$. The pathogen can produce prolific numbers of conidia (via asexual reproduction), thereby causing devastating loss of turf in relatively short periods of time (25). Gray leaf spot is also prevalent on other turfgrass species such as tall fescue (Festuca arundinacea Schreb.) (26) and St. Augustinegrass (Stenotaphrum secundatum Walt.) (21). The fungus causes a similar disease known as blast on forage ryegrasses, millets, and cereal crops, and is known to infect more than 50 gramineous hosts $(1,18,22)$.

Corresponding author: W. Uddin
E-mail: wxu2@psu.edu

Accepted for publication 25 April 2002.

Publication no. D-2002-0611-01R

(C) 2002 The American Phytopathological Society
The outbreaks of gray leaf spot epidemics in recent years have served as an impetus for a further understanding of the pathogen on perennial ryegrass. Genetic isolation of host specific forms, occurrence of recombination, and maintenance of equilibrium between sexual and asexual reproduction are important factors that relate to disease management. Although mutations and parasexual recombinations are generally considered to be sources of genetic diversity and variability in isolates of $M$. grisea causing rice blast disease $(4,42)$, studies have shown that the structure of some populations may be significantly affected by sexual recombination (12). Sexual reproduction is known to be the most important source of genetic variation in other fungi as well (5). It is thus important to understand the occurrence of sexual reproduction in a population, since the genotypes that arise due to recombination should be considered as targets for the development of effective disease control.

The perfect stage of Pyricularia grisea was first described by Hebert (6) in crosses between isolates from cereals and wild grasses. Since then, efforts have been made to produce perithecia on artificial media under controlled conditions using hermaphroditic tester isolates from finger millet and rice (10,34). Although perithecia have been produced on rice plants by concurrent inoculation of compatible strains in the laboratory (20), there have been no reports on the production of perithecia in nature.

As with other ascomycetes, sexual compatibility in $M$. grisea is governed by two alleles at a single mating type locus designated MAT1-1 and MAT1-2 (40). Heterothallic isolates that occur as both MAT1-1 and MAT1-2 compatibility groups are required for the completion of sexual reproduction in a population. These MAT1-1 and MAT1-2 idiomorphs of $M$. grisea have been cloned and sequenced using genomic subtraction (9). The analysis of mating type distribution in a population, along with phylogenetic analysis, offer exceptional power to trace evolutionary history. Mating ability and behavior of nuclei during ascospore formation have also been used as criteria for examining the relationship among different isolates of the fungus, and serve as valuable tools for analyses of various genetic traits (29). The capacity for interfertility and genetic exchange between host-specific forms of $M$. grisea has been demonstrated by several investigators $(10,36,38)$. These studies have provided insight into pathogenicity and virulence (11), host specificity (30), and fungicide resistance (23).

Fertility in $M$. grisea is a complex phenotype. The degree of fertility ranges from strains that are hermaphroditic (both female and male fertile) to those that behave only as male fertile (female sterility) or female fertile (male sterility) in crosses (31). While hermaphroditic isolates produce two rows of perithecia when crossed with compatible fertile tester strains, isolates that form a single band of perithecia are either male fertile or female fertile. In general, isolates from finger millet (Eleusine coracana (L.) Gaertn.), goosegrass (Eleusine indica (L.) Gaertn.), and weeping lovegrass (Eragrostis curvula (Schrad.) Nees are highly fertile, producing abundant ascospores when crossed with $M$. grisea isolates from identical or different hosts. On the contrary, isolates from rice (Oryza sativa L.) are known to have low fertility even when crossed with fertile tester strains $(8,39)$.

Analyses of the population structure of $M$. grisea isolates from perennial ryegrass 
using Pot2 and MGR586 repetitive DNA sequences have shown very little polymorphism among these isolates. The occurrence of three closely related lineages among isolates recovered in 1995 and 1998 suggests a predominantly asexual population (37). To our knowledge, there has been no previous report on the fertility ryegrass and St. Augustinegrass turf. The objectives of the present study were to characterize the mating type distribution, fertility, and degree of sexual compatibility of perennial ryegrass and St. Augustinegrass isolates of $M$. grisea using fertile tester strains from finger millet, rice, and wheat.

\section{MATERIALS AND METHODS}

Isolation and maintenance of Magnaporthe grisea isolates. Samples of perennial ryegrass affected by gray leaf spot were collected from golf courses in California, Kentucky, Massachusetts, New Jersey, New York, Pennsylvania, Virginia, and West Virginia from 1998 and 2001. Additionally, isolates of $M$. grisea from perennial ryegrass collected in 1995 and 1996 were obtained from Andrew Hamblin (University of Illinois), Bruce Clarke (Rutgers, the State University of New Jersey), Ned Tisserat (Kansas State University), Peter Dernoeden (University of Maryland), and Peter Landschoot (Pennsylvania State University). Isolates of $M$. grisea from St. status of $M$. grisea isolates from perennial

Augustinegrass were obtained from Lawrence Datnoff (University of Florida) and Lane Tredway and Lee Burpee (University of Georgia) (Table 1). Grass blades with necrotic lesions and blighted tips were randomly selected from the samples, washed in tap water for 1 to $3 \mathrm{~min}$, and placed on moist filter paper in petri dishes for $24 \mathrm{~h}$ at $25^{\circ} \mathrm{C}$ in order to induce sporulation. Conidia were dislodged onto potato dextrose agar (PDA) plates, and germinating monoconidial isolates of $M$. grisea were transferred to fresh PDA plates after 24 h. For long-term storage, sterilized Whatman filter paper disks were placed on PDA plates, and the mycelium was allowed to grow over the disks. After colonization, the disks were removed from the culture plate and air-dried. The cultures were placed in sterilized envelopes and stored at $-20^{\circ} \mathrm{C}$ and $-80^{\circ} \mathrm{C}$. Prior to fertility assays, isolates were retrieved from storage by plating the disks on PDA (31). A total of 312 monoconidial isolates of $M$. grisea from perennial ryegrass and 62 from St. Augustinegrass were tested for crosscompatibility and distribution of mating types (Table 1).

Standard tester isolates. Identification of mating type and fertility status was determined by pairing each field isolate with the standard tester isolates, KA-3, KA-7, KA-9, GUY-11, BR-48, and BR-116.5. Isolates KA-3, KA-7, KA-9, and GUY-11 were obtained from Jean L. Notteghem

Table 1. Magnaporthe grisea isolates from perennial ryegrass and St. Augustinegrass collected in the United States

\begin{tabular}{llccc}
\hline Host of origin & State & $\begin{array}{c}\text { Monoconidial } \\
\text { isolates }\end{array}$ & $\begin{array}{c}\text { Year of } \\
\text { collection }\end{array}$ & $\begin{array}{c}\text { Golf courses } \\
\text { sampled }\end{array}$ \\
\hline $\begin{array}{l}\text { Lolium perenne } \\
\text { L. perenne }\end{array}$ & California & 8 & 2001 & 1 \\
L. perenne & Illinois & 5 & 1995 & 2 \\
L. perenne & Kansas & 12 & 1995 & 1 \\
L. perenne & Kentucky & 5 & 2000 & 1 \\
L. perenne & Massachusetts & 8 & 2000 & 1 \\
L. perenne & Maryland & 6 & 1995 & 1 \\
L. perenne & New Jersey & 2 & 1995 & 1 \\
L. perenne & New Jersey & 32 & 1998 & 7 \\
L. perenne & New Jersey & 3 & 2000 & 1 \\
L. perenne & New York & 6 & 1998 & 1 \\
L. perenne & Pennsylvania & 3 & 1995 & 1 \\
L. perenne & Pennsylvania & 5 & 1996 & 1 \\
L. perenne & Pennsylvania & 117 & 1998 & 18 \\
L. perenne & Pennsylvania & 41 & 1999 & 3 \\
L. perenne & Pennsylvania & 24 & 2000 & 6 \\
L. perenne & Pennsylvania & 16 & 2001 & 1 \\
L. perenne & Virginia & 14 & 1998 & 2 \\
Stenotaphrum secundatum & Wlorida & 5 & 1998 & 1 \\
S. secundatum & Georgia & 58 & 1998 & 1 \\
\hline & & 4 & 1999 & 1 \\
\hline
\end{tabular}

Table 2. Origins and references of standard tester isolates of Magnaporthe grisea

\begin{tabular}{lllll}
\hline Isolate & Mating type & Place of collection & Host of origin & References \\
\hline KA-3 & MAT1-1 & Uganda & Eleusine coracana & H. Kato \\
KA-7 & MAT1-1 & India & E. coracana & H. Kato \\
KA-9 & MAT1-2 & Uganda & E. coracana & H. Kato \\
GUY-11 & MAT1-2 & French Guyana & Oryza sativa & Leung et al. 1988 \\
BR-48 & MAT1-1 & Brazil & Triticum aestivum & S. Igarashi \\
BR-116.5 & MAT1-2 & Brazil & T. aestivum & A. S. Urashima \\
\hline
\end{tabular}

(CIRAD, Montepellier, France), and isolates BR-48 and BR-116.5 were obtained from Yukio Tosa and Shigeyuki Mayama (Kobe University, Japan). These tester isolates belonged to known mating types, MAT1-1 and MAT1-2 (Table 2), and were hermaphrodites known to possess a high degree of fertility, producing numerous perithecia with isolates of the opposite mating type $(17,33,35)$.

Assessment of mating type. In order to test the mating compatibility, crosses were made by pairing actively growing mycelia of the field isolates and fertile tester strains about $4 \mathrm{~cm}$ apart on oatmeal agar (20 $\mathrm{g}$ of oatmeal and $10 \mathrm{~g}$ of agar in $500 \mathrm{ml}$ of water) plates. The inoculated plates were sealed with Parafilm (Pechiney Plastic Packaging, Inc., Menasha, WI) and incubated at $27^{\circ} \mathrm{C}$ under $12 \mathrm{~h}$ day/night cycles for a week, and then placed at $20^{\circ} \mathrm{C}$ under continuous illumination $\left(76 \mu \mathrm{E} \cdot \mathrm{m}^{-2} \cdot \mathrm{s}^{-1}\right)$ (31). The interface of the two isolates was periodically examined for formation of perithecia using a stereomicroscope. Mating type of a field isolate was designated as the opposite of the tester isolate with which perithecia were produced. The experiment was conducted twice.

Cross-compatibility and fertility. The compatibility between the M. grisea isolates of perennial ryegrass and St. Augustinegrass, and the tester strains was examined by determining the capacity to form perithecia in crosses. Isolates that formed perithecia were designated as male, female, or hermaphroditic according to the nomenclature of Itoi et al. (7): Male fertile isolates formed perithecia only on the side of the tester isolate, while female fertile isolates formed perithecia on the side of the field isolate (did not function as males). Isolates that produced perithecia on both sides of the tester and the field isolate were considered hermaphrodites. The relative degree of fertility was assessed by determining the number of perithecia formed in $5 \mathrm{~mm}^{2}$ of the agar surface. All paired plates were analyzed for fertility after 55 days of incubation. Fertility levels of the isolates were classified as high ( $>20$ perithecia per $5 \mathrm{~mm}^{2}$ ), intermediate (10 to 19 perithecia per $\left.5 \mathrm{~mm}^{2}\right)$, or low $(<10$ perithecia per 5 $\mathrm{mm}^{2}$ ). Isolates that did not produce perithecia were considered infertile $(15,35)$. Perithecia formed in three replicated plates were counted and averaged. Perithecia from each cross were examined for the presence/absence of asci and ascospores by mounting 10 to 15 perithecia on a slide, staining with cotton blue, gently squashing, and then observing under a microscope.

Hermaphroditic tester isolates of the opposite mating types were paired among themselves and assessed for formation of perithecia and production of ascospores. Additionally, M. grisea isolates of St. Augustinegrass that produced perithecia with the tester isolates were crossed between themselves (without fertile testers) to 
check for mating compatibility. Conditions for formation of perithecia were maintained as previously described. The experiment was conducted twice.

\section{RESULTS}

About 20 days after pairing, white masses of hyphae developed at the interface of two heterothallic isolates, which was followed by the development of perithecial initials. Mature perithecia were observed 40 to 55 days after pairing (Fig. $1 \mathrm{~A}$ and $\mathrm{B}$ ). The length and width of the neck and ascocarp in crosses between perennial ryegrass or St. Augustinegrass isolates and the fertile testers varied from 55$130 \times 65-95 \mu \mathrm{m}$ and 70-120 × 65-115 $\mu \mathrm{m}$. Crosses between tester isolates of the opposite mating types produced fertile perithecia with abundant asci and ascospores (Fig. 1C).

Mating type distribution. Of the 1,872 crosses between 312 monoconidial isolates of $M$. grisea from perennial ryegrass and the six hermaphroditic tester isolates, 139 (44.6\%) isolates produced perithecia with either of the six tester isolates. All the isolates from perennial ryegrass produced perithecia only when crossed with MAT1-1 tester strains and belonged to one mating type (MAT1-2).

Of the 372 combinations between the 62 isolates from St. Augustinegrass, 19 $(30.6 \%)$ isolates produced perithecia when mated with the tester isolates. Isolates of MAT1-1 and MAT1-2 mating types were observed among the isolates of St. Augustinegrass obtained from Florida. While 15 isolates belonged to MAT1-1 type, 4 were of the MAT1-2 type. The four isolates from Georgia did not produce perithecia with either of the six tester strains and were sterile.

Assessment of fertility in $M$. grisea isolates. Variation in the degree of fertility as indicated by the development of perithe- cia formed in $5 \mathrm{~mm}^{2}$ of the agar surface was observed among the isolates of perennial ryegrass and St. Augustinegrass. Of the $139(44.6 \%)$ isolates of perennial ryegrass that formed perithecia with the fertile tester strains, $83(59.7 \%)$ were highly fertile ( $>20$ perithecia per $\left.5 \mathrm{~mm}^{2}\right), 33(23.7 \%)$ were intermediately fertile (10 to 19 perithecia per $5 \mathrm{~mm}^{2}$ ), and $23(16.5 \%)$ were low in fertility $(<10$ perithecia per 5 $\left.\mathrm{mm}^{2}\right)$. A total of $173(55.4 \%)$ isolates did not produce perithecia in all possible combinations and were infertile. All the perennial ryegrass isolates that formed perithecia were male-fertile (female sterile). Perithecia produced in these crosses were barren without the formation of asci or ascospores, regardless of their developmental stage. The degree of fertility among the perennial ryegrass isolates of $M$. grisea collected from the various states is shown in Figure 2. The highest frequency of isolates that produced perithecia was from a golf course in New Jersey, where all the isolates produced perithecia with either of the tester strains (data not shown). Isolates obtained from 11 golf courses that included 4 in Pennsylvania, 3 in New Jersey, and 1 each from California, Massachusetts, Maryland, and Kansas did not produce perithecia and were uniformly sterile.

Of the $62 M$. grisea isolates from St. Augustinegrass tested for fertility, 43 $(69.4 \%)$ of the isolates did not produce perithecia with any of the tester isolates. Of the $19(30.6 \%)$ isolates that formed perithecia, $5(26.3 \%)$ were highly fertile (>20 perithecia per $\left.5 \mathrm{~mm}^{2}\right), 7(36.8 \%)$ were intermediately fertile (10 to 19 perithecia per $5 \mathrm{~mm}^{2}$ ), and $7(36.8 \%)$ were low in fertility $\left(<10\right.$ perithecia per $\left.5 \mathrm{~mm}^{2}\right)$. Both male and female fertile isolates were detected among the isolates of St. Augustinegrass. Of the 19 isolates that formed perithecia, 10 isolates were male fertile and 9 were female fertile. Female fertility was predominantly higher in the MAT1-1 isolates (Table 3); however, none of the isolates behaved as hermaphrodites in crosses. While most combinations did not produce asci and ascospores, the crosses involving isolates FAG7.1.1 and FAG15.1.2, and the finger millet tester KA-9, produced perithecia with ascospores. However, it was not possible to isolate ascospore progenies due to the few ascospores produced in these crosses.

Specific compatibilities and variation in the efficiency of the tester isolates was observed in crosses. Of the three tester isolates, KA-3, KA-7, and BR-48, that were compatible with the perennial ryegrass isolates, the finger millet tester strain, KA-7, was most efficient in crosses. A total of 88 isolates formed perithecia with this tester. While 22 isolates were compatible with either of the three tester strains, 3 isolates formed perithecia with all the testers, KA-3, KA-7, and BR-48. Of the 19 isolates of St. Augustinegrass that formed perithecia, a total of 12 isolates were compatible with KA-9 (Table 3). None of the isolates were compatible when crossed with KA-3. Monoconidial isolates obtained from single gray leaf spot lesions formed perithecia with different tester isolates but belonged to the same mating type. Crosses between isolates of St. Augustinegrass of the opposite mating types (without standard tester isolates) did not result in formation of perithecia.

\section{DISCUSSION}

This is the first report in which the mating type distribution and sexual compatibility among the populations of $M$. grisea isolates from perennial ryegrass and St. Augustinegrass have been determined. This was accomplished by using a large number of field isolates and highly fertile hermaphroditic tester isolates of known mating type.
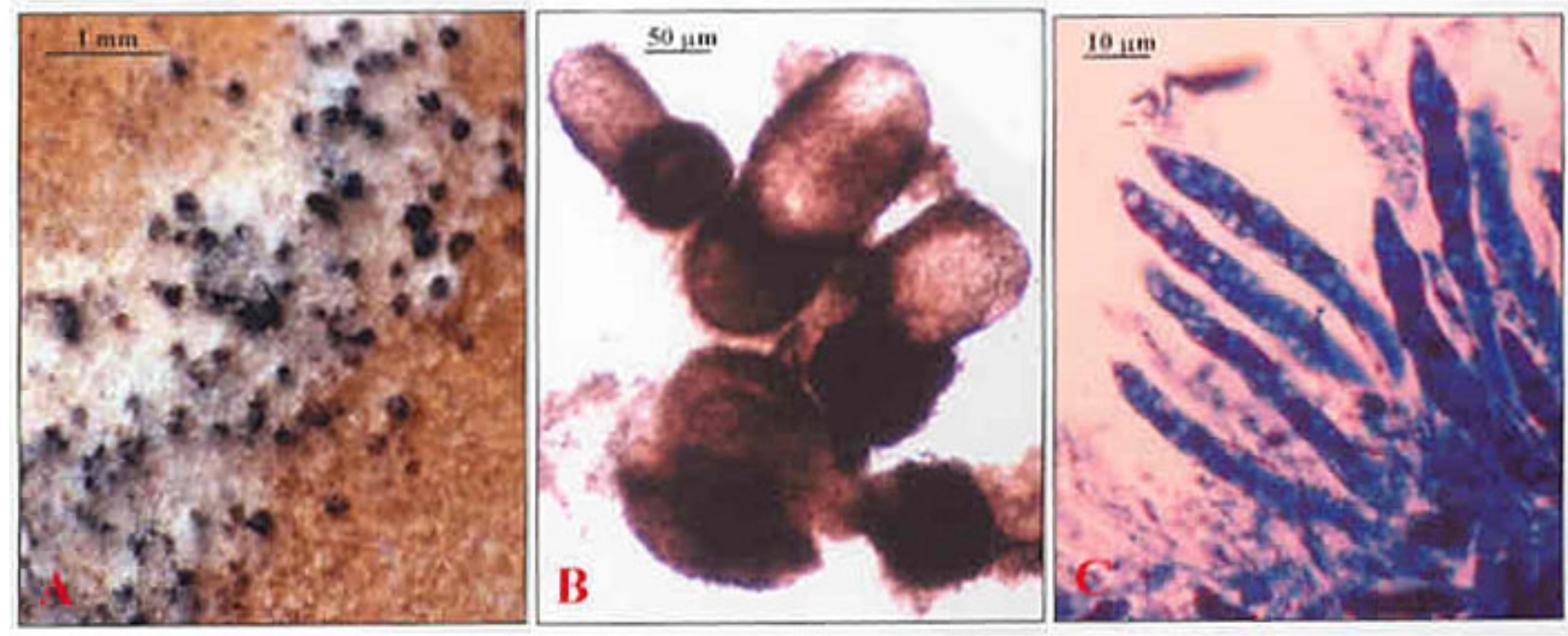

Fig. 1. A and B, Production of perithecia on oatmeal agar by a perennial ryegrass isolate of Magnaporthe grisea, PA3-5, paired with finger millet tester, KA-7. C, Mature asci and ascospores produced in a cross between tester isolates KA-7 and GUY-11. 
A significant percentage of the $M$. grisea isolates of perennial ryegrass isolates were compatible, forming perithecia in laboratory mating experiments. A total of 139 $(44.6 \%)$ isolates of perennial ryegrass and 19 (30.6\%) from St. Augustinegrass produced perithecia with tester strains of the opposite mating type. The remaining isolates did not form perithecia when crossed with the testers and were sterile. It is known that the degree of fertility among $P$. grisea isolates from different hosts ranges from highly fertile isolates to complete sterility (10). Previous reports on cross-compatibility involving $M$. grisea isolates from various hosts have shown that sterility is the norm. In a survey of 718 rice isolates from 20 countries, 528 isolates were infertile and did not form perithecia in cultures (10). Most rice isolates of $M$. grisea from Thailand (16) and India (35) have been reported to be sterile when crossed with hermaphroditic tester isolates.

All the $M$. grisea isolates of perennial ryegrass that formed perithecia with the hermaphroditic tester strains belonged to one mating group, indicating that the chances for sexual recombination may not exist among these isolates. The mating type distribution was consistent, irrespective of the geographic region or year of collection of the isolates. The existence of a single mating type in the perennial ryegrass isolates collected over a 7-year period indicates predominant asexual reproduction. This is in accordance with studies of Viji et al. (37) where mating type genes were used as probes in restriction fragment length polymorphism (RFLP) analysis of the perennial ryegrass isolates. All the isolates tested in the study showed a 4-kb band corresponding to MAT1-2. Although the determination of the mating type is possible with cloned mating type genes, identification of the fertility level of isolates requires hermaphroditic strains of the opposite mating type. The predominance of a single mating type as observed in this study is not uncommon and has been reported on mating type distribution analyses of the rice isolates. In a survey of 467 rice isolates of $M$. grisea from 34 countries, a single mating type (MAT1-1) was found in most of Europe and Africa (17). Similar results have also been reported in Japan, where all the rice isolates tested belonged to the MAT1-1 group (10). However, stud-

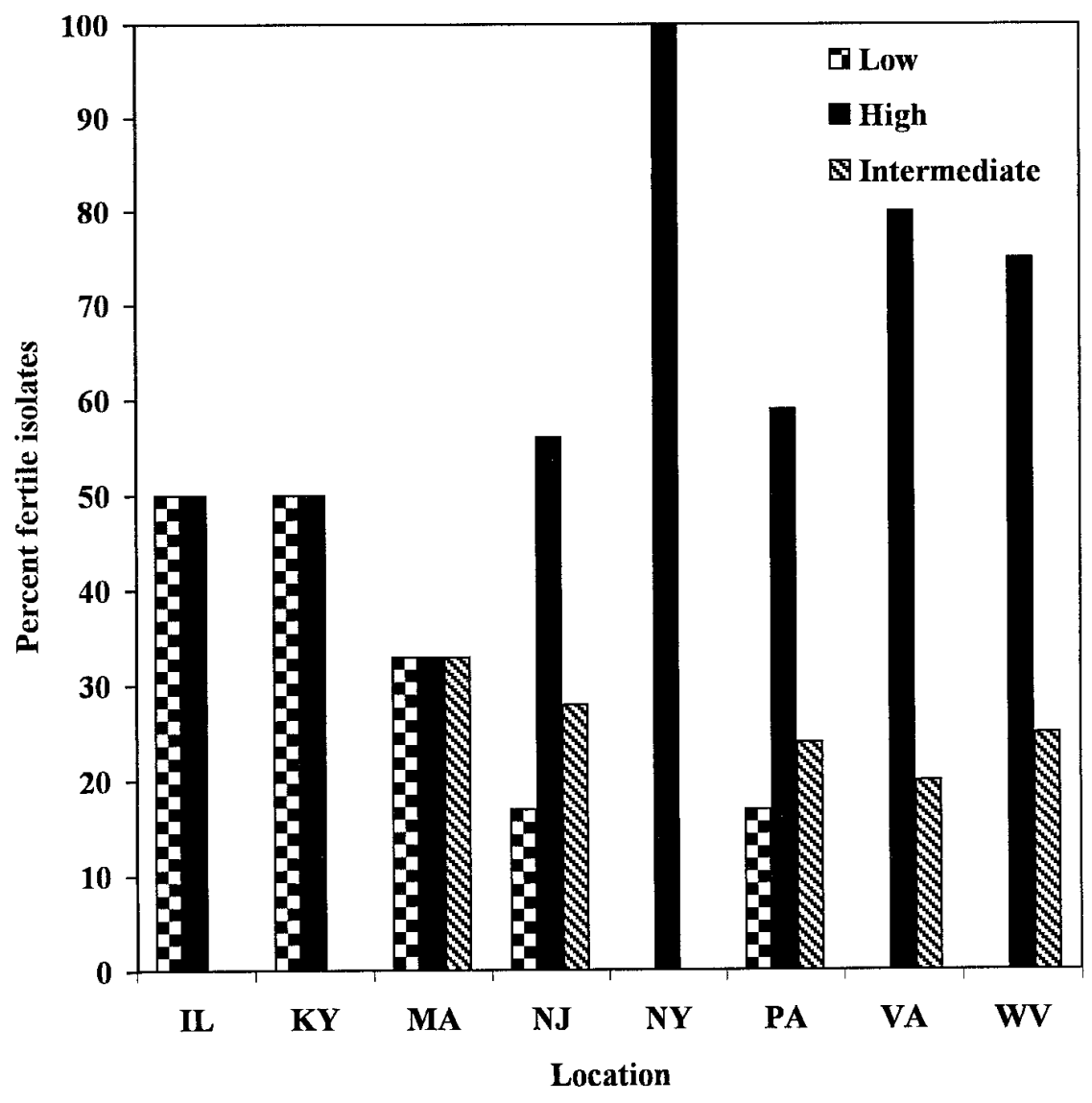

Fig. 2. Percent perennial ryegrass isolates of Magnaporthe grisea from Illinois (IL), Kentucky (KY), Massachusetts (MA), New Jersey (NJ), New York (NY), Pennsylvania (PA), Virginia (VA), and West Virginia (WV) that produced perithecia in each fertility group. Fertility levels of the isolates were assessed by determining the number of perithecia formed in $5 \mathrm{~mm}^{2}$ of the agar surface and classified as high $\left(>20\right.$ perithecia per $\left.5 \mathrm{~mm}^{2}\right)$, intermediate (10 to 19 perithecia per $\left.5 \mathrm{~mm}^{2}\right)$, or low $(<10$ perithecia per $5 \mathrm{~mm}^{2}$ ). ies on the mating type distribution of $M$. grisea isolates from rice, wheat, and finger millet have shown the presence of both mating groups, MAT1-1 and MAT1-2, in varying proportions $(2,19,29,35)$. In our study, the occurrence of both mating types was observed among the isolates of St. Augustinegrass collected from a single site in Florida; however, their frequencies were highly skewed (Table 3). Of the 19 isolates that formed perithecia, 15 belonged to a single mating group (MAT1-1).

The low fertility of the M. grisea isolates of perennial ryegrass as indicated by female sterility suggests that the capacity for expressing the female characteristic might have been lost. Hermaphroditic isolates of $M$. grisea are known to behave as male fertile (female sterile) due to the degeneration of sex (32). Leslie and Klein (14) proposed that many different single mutations could result in female sterility in ascomycetes. However, male fertile isolates are genetically and physiologically simpler and are less prone to random mutations. It has been postulated that even for those isolates retaining functional male capacity, the viability of ascospores would be low when crossed with fertile tester isolates (41). Studies on the fertility of the rice blast pathogen have shown a consistent pattern, where isolates were typically male fertile only $(17,39)$. In our study, both male and female fertile isolates were detected in the isolates of St. Augustinegrass; however, none behaved as hermaphrodites. Crosses between any two isolates of St. Augustinegrass (without tester isolates) were sterile and perithecia were not produced even when the two parents of opposite mating types were used.

As in other studies with rice-infecting isolates of $M$. grisea, the perennial ryegrass isolates produced perithecia without the formation of asci and ascospores, while a few ascospores were observed with the isolates from St. Augustinegrass. However, it is not uncommon to observe such crosses $(10,38)$. Crosses between rice isolates and hermaphroditic finger millet testers have also been shown to produce perithecia devoid of asci and ascospores (38), and very low ascospore viability has been reported in several studies $(10,17)$; however, these abnormalities were not observed in heterothallic matings within finger millet isolates. A variety of genetic abnormalities including gene mutations, chromosomal duplications and heterogeneity, and formation of lagging chromosomes at the time of ascus formation are known to result in sparse survival of ascospores or barren perithecia in $M$. grisea (24). Higher frequency of lagging chromosomes and development of abnormal asci, and reduced number of ascospores in an ascus, have been also observed in crosses between rice and Eleusine pathogens as compared to crosses between Eleusine pathogens $(10,24)$. The inability of the perennial rye- 
grass isolates to produce ascospores in crosses indicates the absence of genetic exchange between the populations of $M$. grisea from perennial ryegrass and those from finger millet and wheat. Although previous studies on the host range, DNA fingerprinting using repetitive sequences, and the comparison of ITS sequences have shown close similarities between the perennial ryegrass and wheat isolates of $M$. grisea (37), the present suggests that hostspecific forms may be reproductively isolated. The presence of a retroelement, grasshopper (grh), exclusively in the Eleusine pathogens (3) also supports the lack of genetic exchange and gene flow between specific populations of $M$. grisea . The lack of ascospore production in crosses with isolates of perennial ryegrass, and the small number of ascospores formed with isolates of St. Augustinegrass, were obstacles to perform further genetic analyses.

It is known that the fertility of a particular cross in terms of perithecia and ascospores produced is dependent on both the tester strain and the isolate tested $(31,32)$. Additionally, host association is an important factor conditioning the fertility of $M$. grisea isolates as documented in several studies $(32,35)$. The tester isolates used in this study have been reported to have high fertility levels producing numerous ascospores in previous studies $(17,35)$. When tester isolates of opposite mating types were crossed, two bands of perithecia with the formation of abundant ascospores were

Table 3. Mating type and fertility of Magnaporthe grisea isolates from St. Augustinegrass when crossed with hermaphroditic tester strains

\begin{tabular}{|c|c|c|c|c|c|}
\hline \multirow[b]{2}{*}{$\begin{array}{l}\text { Isolate } \\
\text { number }\end{array}$} & \multicolumn{5}{|c|}{ Assessment of fertility } \\
\hline & Tester & Mating type $^{\mathrm{a}}$ & Fertility $^{\mathbf{b}}$ & $\begin{array}{l}\text { Sexual structures } \\
\text { produced }\end{array}$ & Perithecia $^{c}$ \\
\hline FAG3.2.1 & KA-7 & MAT1-2 & Male & Perithecia & 8 \\
\hline FAG3.2.2 & BR-48 & MAT1-2 & Male & Perithecia & 18 \\
\hline FAG5.1.1 & KA-9 & MAT1-1 & Female & Perithecia & 16 \\
\hline FAG5.1.2 & KA-9 & MAT1-1 & Female & Perithecia & 4 \\
\hline FAG 5.2.1 & KA-9 & MAT1-1 & Female & Perithecia & 13 \\
\hline FAG6.2.1 & BR-116.5 & MAT1-1 & Male & Perithecia & 5 \\
\hline FAG7.1.1 & KA-9 & MAT1-1 & Male & $\begin{array}{l}\text { Perithecia with } \\
\text { ascospores }\end{array}$ & 16 \\
\hline FAG7.1.1 & GUY-11 & MAT1-1 & Male & Perithecia & 14 \\
\hline FAG8.1.1 & BR-48 & MAT1-2 & Male & Perithecia & 35 \\
\hline FAG9.1.2 & GUY-11 & MAT1-1 & Male & Perithecia & 13 \\
\hline FAG12.1.2 & KA-9 & MAT1-1 & Male & Perithecia & 24 \\
\hline FAG13.1.1 & KA-9 & MAT1-1 & Female & Perithecia & 6 \\
\hline FAG14.2.1 & KA-9 & MAT1-1 & Female & Perithecia & 21 \\
\hline FAG15.1.2 & KA-9 & MAT1-1 & Male & $\begin{array}{l}\text { Perithecia with } \\
\text { ascospores }\end{array}$ & 4 \\
\hline FAG16.1.1 & KA-9 & MAT1-1 & Female & Perithecia & 33 \\
\hline FAG17.1.1 & KA-9 & MAT1-1 & Female & Perithecia & 6 \\
\hline FAG18.1.2 & KA-9 & MAT1-1 & Female & Perithecia & 33 \\
\hline FAG18.1.2 & GUY-11 & MAT1-1 & Female & Perithecia & 22 \\
\hline FAG19.2.1 & KA-9 & MAT1-1 & Male & Perithecia & 8 \\
\hline FAG20.1.2 & BR-116.5 & MAT1-1 & Female & Perithecia & 19 \\
\hline FAG21.1.2 & BR-48 & MAT1-2 & Male & Perithecia & 17 \\
\hline
\end{tabular}

${ }^{a}$ MAT1-1 isolates formed perithecia with MAT1-2 testers, and MAT1-2 isolates formed perithecia when mated with MAT1-1 testers.

${ }^{\mathrm{b}}$ Male fertile isolates formed perithecia on the side of the tester isolate, and female fertile isolates formed perithecia on the side of the field isolate.

${ }^{c}$ Number of perithecia formed in $5 \mathrm{~mm}^{2}$ agar surface. fertile hermaphrodites. fertility in the $M$. grisea isolates of perennial ryegrass as evidenced by the absence of female fertility and ascospore formation. The relatively simple population structure of $M$. grisea isolates of perennial ryegrass as determined by fingerprinting analyses using repetitive elements (37) along with the results shown in this study, indicate the clonality of the pathogen. The presence of a single mating type in all the isolates of perennial ryegrass also supports this. It appears that $M$. grisea isolates from perennial ryegrass persist as reproductively isolated populations in which the sexual stage may not be effectively linked to genetic variation and disease spread. Although male and female fertile isolates of both mating types were observed among the isolates of St. Augustinegrass, the highly skewed mating type ratios and the formation of few ascospores indicate that even if perithecia are produced in nature, it probably is infrequent and insignificant in gray leaf spot epidemiology.

\section{ACKNOWLEDGMENTS}

We thank Andrew Hamblin, Bruce Clarke, Jean-Loup Notteghem, Lane Tredway, Lawrence Datnoff, Lee Burpee, Peter Dernoeden, Peter Landschoot, Ned Tisserat, Shigeyuki Mayama, and Yukio Tosa for providing isolates of Magnaporthe grisea used in this study. We also manuscript. This research was supported by the grant provided by the Pennsylvania Turfgrass Council. produced, indicating that the isolates were

This study indicates the low levels of

\section{LITERATURE CITED}

1. Bain, D. C., Patel, B. M., and Patel, M. V. 1972. Blast of ryegrass in Mississippi. Plant. Dis. Rep. 56:210

2. Dayakar, B. V., Narayanan, N. N., and Gnanamanickam, S. S. 2000. Crosscompatibility and distribution of mating type alleles of the rice blast fungus Magnaporthe grisea in India. Plant Dis. 84:700-704.

3. Dobinson, K. F., Harris, R. E., and Hamer, J. E. 1993. Grasshopper, a long terminal repeat (LTR) retroelement in the phytopathogenic fungus Magnaporthe grisea. Mol. PlantMicrobe Interact. 6:114-126.

4. Genovesi, A. D., and Magill, C. W. 1976 Heterokaryosis and parasexuality in Pyricularia oryzae Cavara. Can. J. Microbiol. 22:531-536.

5. Goodwin, S. B. 1997. The population genetics of Phytophthora. Phytopathology 87:462473.

6. Hebert, T. T. 1971. The perfect stage of Pyricularia grisea. Phytopathology 61:83-87.

7. Itoi, S., Mishima, T., Arase, S., and Nozu, M 1983. Mating behavior of Japanese isolates of Pyricularia oryzae. Phytopathology 73:155158.

8. Itoi, S., Yamamoto, J., Karino, S., Arase, S., and Kato, H. 1980. Hermaphroditic isolates of Pyricularia isolated from ragi, Eleusine coracana (L.) Gaertn. Ann. Phytopathol. Soc. Jpn. 46:549-552.

9. Kang, S., Chumley, F. G., and Valent, B. 1994. Isolation of the mating-type genes of the phytopathogenic fungus Magnaporthe grisea using genomic subtraction. Genetics 138:289-296.

10. Kato, H., and Yamaguchi, T. 1982. The perfect stage of Pyricularia oryzae Cav. from rice plants in culture. Ann. Phytopathol. Soc. Jpn. 48:607-612.

11. Kolmer, J. A., and Ellingboe, A. E. 1988 Genetic relationships between fertility and pathogenicity and virulence to rice in Magnaporthe grisea. Can. J. Bot. 66:891-897.

12. Kumar, J., Nelson, R. J., and Zeigler, R. S. 1999. Population structure and dynamics of Magnaporthe grisea in the Indian Himalayas. Genetics 152:971-984.

13. Landschoot, P. J., and Hoyland, B. F. 1992. Gray leaf spot of perennial ryegrass turf in Pennsylvania. Plant Dis. 76:1280-1282.

14. Leslie, J. F., and Klein, K. K. 1996. Female fertility and mating type effects on effective population size and evolution in filamentous fungi. Genetics 144:557-567.

15. Leung, H., and Williams, P. H. 1985. Genetic analysis of electrophoretic enzyme variants, mating type and hermaphroditism in Pyricularia oryzae Cavara. Can. J. Genet. Cytol. 27:697-704.

16. Mekwatanakarn, P., Kositratana, W., Phromraksa, T., and Zeigler, R. S. 1999. Sexually fertile Magnaporthe grisea rice pathogens in Thailand. Plant Dis. 83:939-943.

17. Notteghem, J. L., and Silue, D. 1992. Distribution of the mating type alleles in Magnaporthe grisea populations pathogenic on rice. Phytopathology 82:421-424.

18. Ou, S. H. 1985. Rice Diseases. Commonwealth Mycological Institute, Kew, Surrey, England.

19. Priyadarisini, V. B., Viji, G., and Gnanamanickam, S. S. 1999. Mating type distribution, fertility and pathogenicity of rice isolates of Magnaporthe grisea in four rice growing regions of India. Ind. Phytopathol. 52:28-34.

20. Silue, D., and Notteghem, J. L. 1990. Production of perithecia of Magnaporthe grisea on rice plants. Mycol. Res. 94:1151-1152.

21. Smiley, R. W., Dernoeden, P. H., and Clarke, B. B. 1992. Compendium of Turfgrass Diseases. American Phytopathological Society, 
St.Paul, MN

22. Sundaram, N. V., Palmer, L. T., Nagarajan, K., and Prescott, J. M. 1972. Disease survey of sorghum and millet in India. Plant Dis. Rep. 56:740-743

23. Taga, M., Nakagawa, H., Tsuda, M., and Ueyama, A. 1978. Ascospore analysis of kasugamycin resistance in the perfect stage of Pyricularia oryzae. Phytopathology 68:815817.

24. Tanaka, Y., Murata, N., and Kato, H. 1979. Behavior of nuclei and chromosomes during ascus development on the mating between either rice-strain or weeping lovegrass-strain and ragi-strain of Pyricularia. Ann. Phytopathol. Soc. Jpn. 45:182-191.

25. Uddin, W. 1999. Gray leaf spot 'blasts' U.S. golf course turf. Golf Course Management 67:52-56.

26. Uddin, W., Burpee, L. L., and Stevenson, K. L. 1999. Influence of temperature, leaf wetness duration, and turfgrass age on development of gray leaf spot (blast) of Festuca arundinacea. Pages 136-141 in: Int. Conf. Plant Prot. Tropics, 5th, Kuala Lumpur.

27. Uddin, W., Soika, M. D., Moorman, F. E., and Viji, G. 1999. A serious outbreak of blast disease (gray leaf spot) of perennial ryegrass in golf course fairways in Pennsylvania. Plant Dis. 83:783

28. Uddin, W., Viji, G., and Stowell, L. 2002.
First report of gray leaf spot on perennial ryegrass turf in California. Plant Dis. 86:75.

29. Urashima, A. S., Igarashi, S., and Kato, H. 1993. Host range, mating type, and fertility of Pyricularia grisea from wheat in Brazil. Plant Dis. 77:1211-1216.

30. Valent, B., and Chumley, F. G. 1987. Genetic analysis of host species specificity in Magnaporthe grisea. Pages 83-93 in: Molecular Strategies for Crop Protection. C. J. Arntzen and C. Ryan, eds. A. R. Liss, New York.

31. Valent, B., Crawford, M. S., Weaver, C. G., and Chumley, F. G. 1986. Genetic studies of fertility and pathogenicity in Magnaporthe grisea (Pyricularia grisea). Ia. State J. Res. 60:569-594.

32. Valent, B., Leonard, F., and Chumley, F. G. 1991. Magnaporthe grisea genes for pathogenicity and virulence identified through a series of backcrosses. Genetics 127:87-101.

33. Viji, G., and Gnanamanickam, S. S. 1996. Biological control of blast disease of finger millet (Eleusine coracana L.) and an analysis of fertility of Magnaporthe grisea. Curr. Sci. 11:144-147.

34. Viji, G., and Gnanamanickam, S. S. 1996. Effect of cultural factors on the formation of perithecia in Magnaporthe grisea. Kavaka 24:51-56

35. Viji, G., and Gnanamanickam, S. S. 1998. Mating type distribution and fertility status of
Magnaporthe grisea populations from various hosts in India. Plant Dis. 82:36-40.

36. Viji, G., Gnanamanickam, S. S., and Levy, M 2000. DNA polymorphisms of isolates of Magnaporthe grisea from India that are pathogenic to finger millet and to rice. Mycol. Res. 104:161-167.

37. Viji, G., Wu, B., Kang, S., Uddin, W., and Huff, D. R. 2001. Pyricularia grisea causing gray leaf spot of perennial ryegrass turf: Population structure and host specificity. Plant Dis. 85:817-826.

38. Yaegashi, H. 1977. On the sexuality of blast fungi, Pyricularia spp. Ann. Phytopathol. Soc. Jpn. 43:432-439.

39. Yaegashi, H., and Nishihara, N. 1976. Production of the perfect stage in Pyricularia from cereals and grasses. Ann. Phytopathol. Soc. Jpn. 42:511-515

40. Yoder, O. C. Valent, B and Chumley, F 1986. Genetic nomenclature and practice for plant pathogenic fungi. Phytopathology 76:383-385.

41. Zeigler, R. S. 1998. Recombination in Magnaporthe grisea. Annu. Rev. Phytopathol. 36:249-275.

42. Zeigler, R. S., Scott, R. P., Leung, H., Bordeos, A. A., Kumar, J., and Nelson, R. J. 1997. Evidence of parasexual exchange of DNA in the rice blast fungus challenges its exclusive clonality. Phytopathology 87:284-294. 